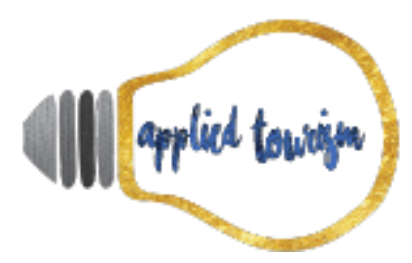

3(1), 2018, p. 147-169

\title{
IMPACTOS DAS RELAÇÕES DE HOSPITALIDADE E HOSTILIDADE ENTRE STAKEHOLDERS SOBRE A COMPETITIVIDADE DE DESTINOS TURÍSTICOS
}

\author{
Aristides Faria Lopes dos Santos \\ Doutorando em Hospitalidade pela Universidade Anhembi Morumbi \\ Professor no IF de São Paulo (Câmpus Cubatão) \\ aristidesfaria@ifsp.edu.br \\ Elizabeth Kyoko Wada \\ Docente em Hospitalidade da Universidade Anhembi Morumbi
}

Recebido: 06 de setembro, 2017

Aprovado: 15 de janeiro, 2018

\section{RESUMO}

As relações de hospitalidade/hostilidade entre stakeholders exerce influência sobre a competitividade dos destinos turísticos? Para responder a este problema foi desenvolvido estudo de casos múltiplos com abordagem qualitativa que considerou o poder público enquanto organização gestora do destino (DMO), atuando como líder na gestão local. Foram tomados como objetos de estudo os municípios de Cubatão, Itanhaém e Santos, localizados no litoral do estado de São Paulo, região sudeste brasileira. Como técnica de coleta de dados foi feita pesquisa bibliográfica, pesquisa documental, foram aplicadas entrevistas pessoais semiestruturadas com dirigentes municipais de turismo e stakeholders indicados por estes. Verificou-se que quão mais colaborativas forem as relações entre a DMO e seus stakeholders, maiores serão os impactos sobre a competitividade da destinação, entretanto, foi identificado que nos casos analisados a DMO não pratica a gestão do relacionamento com seus stakeholders de modo sistemático, o que parece ser contrário aos objetivos setoriais.

Palavras-chaves: Hospitalidade; Serviços; Stakeholders; Competitividade; Turismo. 


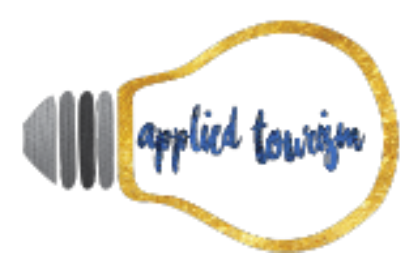

3(1), 2018, p. 147-169

\section{INTRODUÇÃO}

O turismo enquanto atividade econômica e social complexa tem o potencial de fomentar o desenvolvimento de cidades, regiões e mesmo nações onde houver fluxos de visitantes e, por consequência, de insumos para atender a tal demanda.

A Organização Mundial do Turismo (OMT) (2003), organismo das Nações Unidas que trata dos assuntos do setor em âmbito global, afirma que muitas nações dependem do dinamismo da atividade turística como principal fonte geradora de renda, emprego, crescimento do setor privado e do consequente aperfeiçoamento da infraestrutura. Em vista dessa complexidade e amplitude, a mesma entidade conceitua o turismo como as atividades das pessoas que viajam e permanecem em lugares fora de seu ambiente habitual por não mais de um ano consecutivo para lazer, negócios ou outros objetivos.

Para contextualizar o entendimento sobre turismo cabe citar Panosso Netto (2010, p. 33), quem afirma que "o fenômeno de saída e de retorno do ser humano do seu lugar habitual de residência [...] pressupõe hospitalidade, encontro e comunicação com outras pessoas e utilização de tecnologia [...], o que vai gerar experiências variadas e impactos diversos". A visão do autor é pertinente para esta pesquisa já que cita, sobretudo, o "encontro" entre turistas e residentes, pressuposto, justamente, das relações de hospitalidade e/ou hostilidade, que são tema central neste estudo.

As relações de hospitalidade/hostilidade entre stakeholders exerce influência sobre a competitividade dos destinos turísticos brasileiros? Para responder a este problema de pesquisa foi desenvolvido estudo de casos múltiplos sobre três municípios localizados no litoral do estado de São Paulo, região sudeste brasileira, entre os meses de janeiro e agosto de 2015.

Os resultados obtidos a partir daquela pesquisa serviram de base para a proposição de pesquisa quantitativa em desenvolvimento no presente e a ser aplicada na mesma região 


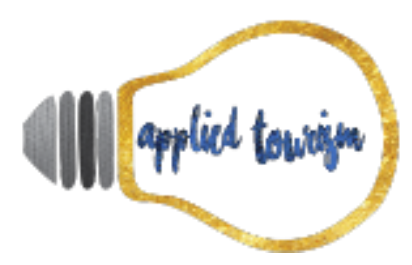

3(1), 2018, p. 147-169

turística em questão. Como objeto de estudo, então, foram escolhidos os municípios de Cubatão, Itanhaém e Santos, todos localizados na Região Metropolitana da Baixada Santista, região administrativa estabelecida por meio da Lei Complementar n ${ }^{\circ} 815$, de 30 de julho de 1996. Além destes, outros seis municípios compõem a região: Bertioga, Guarujá, Mongaguá, Peruíbe, Praia Grande e São Vicente.

A determinação destes municípios como objeto de estudo fundamentou-se em quatro motivações essenciais: primeiro, o fato de as três cidades fazerem parte da mesma região administrativa (sistema de governança e território em comum); depois, a existência de Secretarias Municipais de Turismo em todas as três cidades (organizações gestoras do destino), em seguida, a existência de Conselhos Municipais de Turismo (COMTURs) (espaços para participação societal) e, por fim, a complementaridade que a oferta de atrativos, produtos e serviços representa para a região turística como um todo (diversidade de oferta turística).

O objetivo da pesquisa foi identificar como a organização gestora do destino gerencia suas relações com os stakeholders do setor de viagens e turismo. A fim de alcançar este objetivo, procedeu-se, como visto, um estudo de casos múltiplos, que tendem a ser menos "vulneráveis" em relação aos estudos de casos únicos (Yin, 2015).

Como técnica de coleta de dados foi empregada a pesquisa bibliográfica, a pesquisa documental, a aplicação de entrevistas pessoais semiestruturadas junto a dirigentes municipais de turismo e, em seguida, a dois stakeholders indicados por estes. Adotou-se a estratégia da "bola de neve" ou, em inglês, snowball sampling para identificar e aplicar tais entrevistas com os profissionais indicados como stakeholders da organização gestora do destino.

Os dados coletados nas fases de pesquisa bibliográfica e pesquisa documental foram tratados em duas seções conceituais e em uma voltada à caracterização do objeto de estudo, 


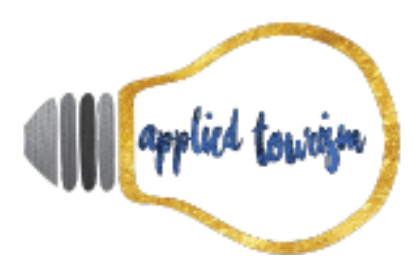

3(1), 2018, p. 147-169

respectivamente. Já dados coletados a partir das entrevistas foram tratados, primeiro, por meio de transcrição (Gibbs, 2009) e, depois, por análise de conteúdo (Bardin, 2011).

A abordagem no tratamento dos dados coletados foi qualitativa, com base na abordagem dos stakeholders, pois se julgou pertinente compreender a complexidade das relações de hospitalidade e hostilidade entre o poder público e os diversos grupos ou indivíduos que influenciam ou sofrem influência - direta ou indireta - da ação governamental.

O projeto de pesquisa foi originalmente elaborado durante o segundo semestre do ano de 2014. A primeira fase de coleta de dados foi composta pela pesquisa bibliográfica e a pesquisa documental, que foram executadas ente janeiro a abril de 2015. A segunda fase foi composta pela pesquisa de campo, que contou com a aplicação das entrevistas citadas, que foram realizadas entre os meses de maio e junho do mesmo ano. O tratamento dos dados coletados, a análise e a discussão dos resultados foi realizada em julho e agosto.

O artigo foi organizado em quatro seções, sendo a primeira o referencial teórico sobre hospitalidade, serviços e consumo de serviços ligados ao turismo. A segunda trata da abordagem dos stakeholders e de competitividade no setor de viagens e turismo. A terceira parte é uma caracterização da macrorregião estudada e de cada um dos municípios que compõem o objeto de estudo. A quarta trata da análise e discussão dos resultados da pesquisa, seguida pelas considerações finais.

\section{REFERENCIAL TEÓRICO}

Apresenta-se a seguir o referencial teórico adotado para fundamentar esta pesquisa. As duas próximas seções foram elaboradas a partir do tratamento dos dados coletados na fase de pesquisa bibliográfica. 


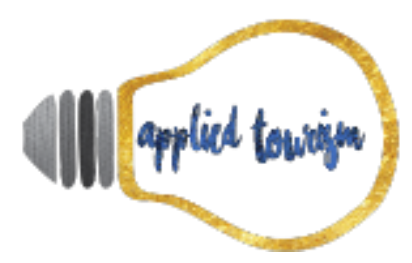

3(1), 2018, p. 147-169

\section{Hospitalidade e Serviços}

O objetivo desta seção é discutir a hospitalidade no contexto comerciai, ou seja, no gerenciamento das relações entre prestadores e consumidores de serviços com vistas ao bom desempenho organizacional, à obtenção de vantagens competitivas e competitividade.

No sentido de conceituar o termo hospitalidade, esta investigação adota como referencial a visão de Lashley (2000), que compreende a hospitalidade como um conjunto de comportamentos originários da base da sociedade, os quais envolvem elementos como o altruísmo e a beneficência, além de um amplo universo de atividades e relações humanas que acontecem concomitantemente em três dimensões ou domínios: comercial, privado e social.

As relações de prestação/consumo de serviços de hospitalidade estão "dentro" do domínio comercial, como propõe o autor. Neste sentido, torna-se possível inferir que o gesto de receber e acolher bem as pessoas pode se configurar como uma vantagem competitiva para as organizações, ou seja, o estabelecimento e a manutenção de relações comerciais alicerçadas na confiança e na ética, por exemplo, podem converter-se na sustentabilidade do negócio.

Ainda que motivadas, mediadas e/ou mantidas por uma relação de negócios, as relações interpessoais no domínio comercial podem sim ser consideradas relações de hospitalidade ou, em oposição, de hostilidade. A gestão dessas relações pode, desse modo, ser profissional, ensaiada e planejada, o que não descaracteriza necessariamente a boa intencionalidade do prestador do serviço.

Isso pode impactar a percepção de qualidade dos serviços consumidos? Na visão de Caon $(2008,10)$, sim. Conforme o autor, a satisfação do cliente depende em grande parte do desempenho do prestador de um determinado serviço por ocasião de sua interação com o cliente, que é simultânea ao efetivo consumo - o que caracteriza os serviços propriamente. 


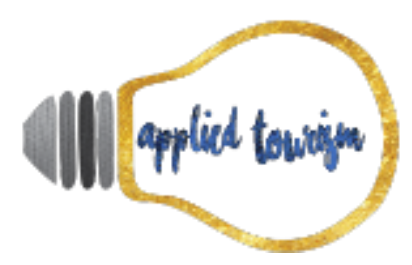

3(1), 2018, p. 147-169

Gotman $(2009,7)$ aponta a existência e práxis do "sorriso comercial", ou seja, um sorriso cortês "endereçado indiferentemente não a uma pessoa em particular, mas a todo cliente em potencial". Esse tipo de postura ou encenação do "bem receber" faz parte de um todo complexo, que tangencia a questão da motivação para oferecer hospitalidade.

Ainda segundo a autora, "A atenção e o serviço são contratuais e não objetos de dádiva e o cliente é qualificado pelas "exigências" relacionadas a regra do preço justo que mediatiza as relações sociais" (GOTMAN, 2009, 7). A autora compreende que entre o valor intrínseco e o compromisso tácito da "dádiva" e a prestação de dado serviço há uma linha tênue que separa a necessidade de retribuição das relações comerciais efêmeras, mediadas por contratos e trocas econômicas daquelas que inserem os protagonistas em um círculo de prestação e retribuição.

Segundo Quadros $(2011,55)$, "resgatar os comportamentos e atitudes que promovem a troca mútua e a consequente identificação empática favorece um forte vínculo emocional e cultural entre o prestador de serviços e hóspede/cliente". Essa vinculação não se reduz aos prestadores de serviços e seus clientes, mas parece se referir também ao relacionamento entre os demais públicos envolvidos. Naturalmente, não impacta apenas a remuneração pelo serviço, mas a qualidade do "pacote de valor" como um todo, que é composto, também, pelo bem em questão, o contexto no qual ocorre essa relação e as experiências anteriores dos consumidores.

Conforme Brito e Brito (2012, 71), o "valor criado não é necessariamente valor apropriado; enquanto o custo de oportunidade e disposição a pagar definem o valor criado, preço e custo definem o valor apropriado". Os autores propõem a análise sobre empresas que criam valor acima da média de seus segmentos de atuação e, com isso, podem "explorar a diferença entre o preço [médio praticado pelo mercado] e a máxima disposição a pagar [pelos clientes efetivos e em potencial] (...)". 


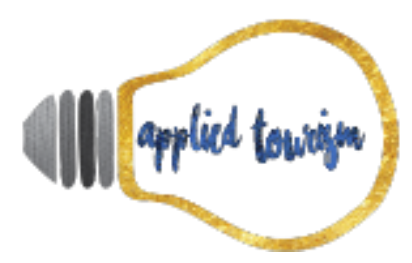

3(1), 2018, p. 147-169

O desenvolvimento da capacidade de oferecer hospitalidade e não de simplesmente servir, assumindo plenamente o papel de anfitrião, pode orientar a um dos caminhos possíveis para que as organizações incorporem de forma estratégica a hospitalidade como um diferencial competitivo - tanto no trato direto com o cliente quanto em relação aos múltiplos stakeholders (Wada \& Moretti, 2014, 97). Mais especificamente sobre as percepções do turista/consumidor sobre as características elementares dos serviços, destaca-se, ao contrário dos bens materiais, a intangibilidade, ou seja, sua imaterialidade. Isso significa que os serviços são bens efêmeros, que têm seu efetivo consumo condicionado a "momentos" que dependem da interação entre prestador e consumidor final.

A partir do exposto foi possível elaborar um primeiro pressuposto a ser investigado: as relações de hospitalidade inerentes ao domínio comercial podem influenciar tanto positiva quanto negativamente o desempenho do setor de viagens e turismo em uma dada destinação (P1).

\section{Abordagem dos Stakebolders e Competitividade}

Esta seção objetiva discutir a viabilidade, entre tantas outras possibilidades, de aplicação da abordagem dos stakeholders para a análise dos fatores que influenciam sobre a competitividade do setor de viagens e turismo em um destino turístico.

De acordo com Freeman (1984, 5, tradução do autor), stakebolders "são todos os indivíduos, grupos ou organizações que são afetados ou afetam outros stakeholders no alcance do objetivo de uma determinada empresa". Tal compreensão possui foco no relacionamento estratégico entre a organização ${ }^{\mathrm{I}}$ e seus públicos de interesse, fornecendo elementos para a elaboração de estratégias eficazes de relacionamento, como parte do posicionamento mercadológico das organizações.

\footnotetext{
' Conforme Valeriano (2001, p. 6), "o ato de organizar uma entidade consiste em atribuir a ela uma estrutura (suas partes - esqueleto e os músculos) e estabelecer as funções das partes (como se interagem, quem faz o que), isto é, seu relacionamento ou funcionamento (estrutura organizacional), para que ela cumpra suas missões ou atinja seus objetivos, permanentes ou não";
} 


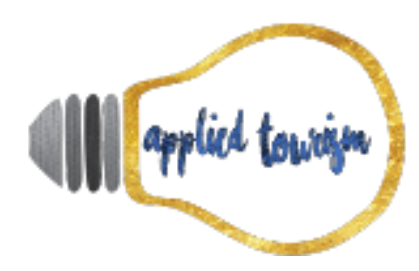

3(1), 2018, p. 147-169

Freeman já apontava na década de 1980 que determinado stakebolder pode desempenhar mais de um papel para diferentes grupos de influência, isto é, um empregado também pode ser cliente, consumindo o produto ou serviço ofertado pela mesma empresa e, ainda, ser morador da vizinhança, por exemplo.

Acerca da classificação dos stakebolders, Mitchell, Agle \& Wood (1997, p. 854), sugerem que as organizações identifiquem seus stakeholders por meio de três características elementares (em negrito), a saber: poder: no que se refere à posse ou obtenção de recursos coercitivos, como forma e imposição em relação à organização; legitimidade: no que se refere a uma percepção generalizada ou uma suposição de que as ações de uma entidade são desejadas, próprias ou apropriadas dentro de algum sistema de normas, valores, crenças e definições, socialmente definidas; e urgência: no que se refere às relações entre os gestores e os stakebolders, como ações de natureza imediata que causam impacto na organização.

A interseção dessas três características citadas indica a relevância para a empresa e a prioridade de atenção e cuidado com que cada grupo deve ser tratado. Além disso, cria três grandes grupos de stakeholders: o grupo dos latentes, que possuem um dos três atributos conforme quem os avalia, o grupo dos expectantes, formado pelos tipos adormecido, discricionário ou reclamante, e que reúnem dois atributos; e grupo dos definitivos, formado pelos stakeholders que possuem os três atributos concomitantemente.

No mesmo sentido, Stoner \& Freeman (1999) afirmam que cada organização possui diferentes públicos de influência - grupos, indivíduos ou organizações - e cada um desses têm diferentes reivindicações - coerentes ou não. Do mesmo modo, Freeman \& McVea (2001) apontam que as organizações têm de gerenciar seus stakebolders no sentido de se anteciparem a suas demandas, pois isso tende a possibilitar que seus gestores se antecipem a eventuais influências negativas desses grupos. 


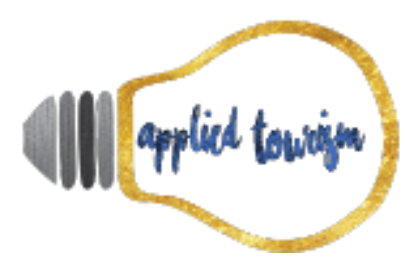

3(1), 2018, p. 147-169

Para Carroll \& Buchholtz (2003), um stakeholder pode ser compreendido enquanto um indivíduo ou grupo que se constitui em um ou mais desses "stakes" em relação ao negócio de uma empresa. Assim como um stakeholder pode ser afetado pode afetar as atividades das organizações, suas decisões ou práticas.

O envolvimento das organizações com seus grupos de interesses requer conhecimento para que se tenha uma relação que seja construtiva e produtiva para os envolvidos no negócio. Compreender as expectativas da sociedade em relação à conduta social e ética das organizações se tornou essencial, pois a pressão exercida por grupos que podem estar ligados - ou virem estar-, direta ou indiretamente ao negócio já é uma realidade (Junqueira $\&$ Wada, 2011).

Para aproximar a abordagem dos stakeholders com os estudos sobre a obtenção de vantagens competitivas e de competitividade, este artigo retoma Porter $(1999,13)$, quem aponta que alcançar um dado nível de competitividade “(...) resulta da produtividade com que as empresas numa determinada localidade são capazes de utilizar os insumos para a produção de bens e serviços valiosos".

Ainda nos anos 1990 o autor introduziu a discussão sobre a influência dos clusters ou "aglomerados" sobre a competitividade de um determinado território. O autor os definiu como "concentrações geográficas de empresas, fornecedores, setores relacionados e instituições especializadas existentes em determinada área de um país, estado ou cidade". O autor propôs, também, a teoria do "Diamante", que sugere que "a rivalidade local, a existência de clientes exigentes e a sofisticação dos fornecedores locais favorecem a competitividade, através do estímulo e do apoio à alta produtividade e da rapidez na inovação" (Porter, 1999, 22). Porter acreditava que a competição poderia exercer influência sobre os níveis de qualidade exigidos pelos clientes e as políticas de preço praticadas junto aos fornecedores. 


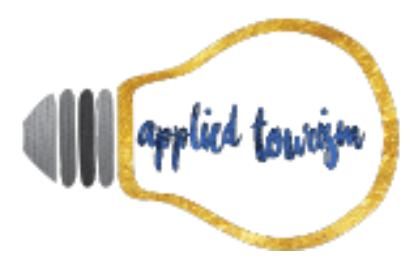

3(1), 2018, p. 147-169

A articulação entre os stakebolders resultará em um determinado nível de competitividade desse território. Isso significa afirmar que a coordenação de esforços poderá favorecer um determinado grupo de empresas em detrimento a outras externas a seu cluster. Conforme Porter (1998, 81), "a host linkages among cluster members results in a whole greater than the sum of its parts", ou seja, a sinergia é um resultado da articulação planejada de esforços, que resulta em impactos mais poderosos que mera soma de esforços individuais.

Uma vez que a percepção de um aglomerado "dentro" de um território físico, composto por stakeholders em constante relacionamento para a consecução de resultados finais (produção de bens ou serviços), é possível compreender os clusters como sistemas abertos, que recebem inputs e entregam outputs. Assim, outro conceito relevante, proposto por Altenburg, Hillebrand \& Meyer-Stamer (1998, 15), é o da "competitividade sistêmica".

Os autores, com base na teoria do "Diamante" proposta por Michael Porter, sugerem que há níveis nos quais os stakebolders de determinado aglomerado se relacionam. No nível micro estão as empresas de menor porte, suas redes e seus esforços contra eventuais externalidades.

No nível meso, surge a figura do poder público, emergem as políticas públicas de regulação do mercado, as agremiações empresariais e o terceiro setor. No nível macro estão as condições gerais do mercado econômico e financeiro, que são os efeitos conjunturais da economia global. No nível meta residem as singularidades e particularidades sociais, culturais e as capacidades locais/nacionais de estabelecerem estratégias competitivas globais.

Este trabalho analisa a influência da ação (ou da inatividade) governamental sobre a competitividade de um determinado setor de mercado, então cabe citar Porter $(2008,10)$ quem recomenda que o Governo - e suas intervenções por meio de leis e (des)regulamentações -, por outro lado, não seja compreendido como uma força competitiva - ao lado das outras cinco propostas pelo autor (concorrentes estabelecidos, 


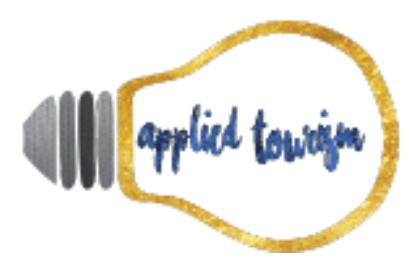

3(1), 2018, p. 147-169

clientes poderosos, compradores poderosos, novos competidores (entrantes) e oferta substituta, alternativa -, pois sua interferência é indireta sobre o mercado, enquanto as ações dos demais elementos impactam diretamente sobre a competitividade do cluster.

Estudo sobre o estado atual de pesquisas sobre competitividade turística no Brasil revelou que “(...) esta área de investigação ainda está incipiente nos estudos brasileiros, que se mantêm com foco em um determinante da competitividade, mas não na competitividade do destino com abrangência multidimensional" (Miki, Gandara \& Muñoz, 2012, 212). Assim, este trabalho buscou desviar-se desse rumo e estudar a complexidade das relações interinstitucionais (forças competitivas) do setor de viagens e turismo no contexto do litoral paulista.

A partir do referencial teórico apresentado, tornou-se possível determinar um segundo pressuposto a ser investigado: as organizações gestoras dos destinos analisados têm seus stakeholders identificados e mapeados, mantendo diálogo formal com os mesmos (P2).

Recentes estudos (2015-2017) apontam para convergências possíveis entre teorias e práticas de gestão do turismo (Vajirakachorn \& Chongwatpol (2017); Peroff et al. (2017); Svensson (2017)), de gerenciamento da hospitalidade no contexto organizacional (Nazarian, et al. (2017); In, et al. (2017)), do emprego das tecnologias da informação e comunicação neste contexto (Adukaaite, et al. (2016); Boonstra, et al. (2015)) e da abordagem dos stakeholders, conforme proposto neste estudo (Line \& Wang (2017); Theodoulidis, et al. (2017); Saito \& Ruhanen (2017)).

\section{APLICAÇÃO DO ESTUDO DE CASOS MÚLTIPLOS}

Esta seção é dedicada a caracterização do objeto de estudo escolhido para compor este estudo de casos múltiplos. O objetivo foi detalhar a justificativa pela determinação do objeto de estudo e contextualizar a relevância destes casos no mercado brasileiro. 


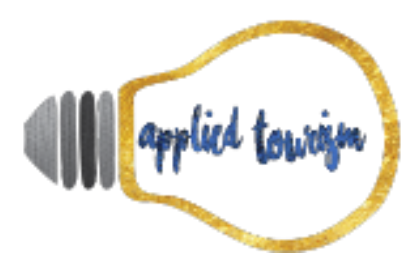

3(1), 2018, p. 147-169

\section{Caracterização do objeto de estudo}

O estado de São Paulo localiza-se na região sudeste do Brasil e possui em seu território de 248.222,362 km² um total de 645 municípios, cuja população total é de 43.674 .533 de habitantes, conforme dados projetados pela Fundação Seade para o ano de 2017 a partir do Censo demográfico brasileiro de 2010. A Região Metropolitana da Baixada Santista (RMBS) é composta por nove cidades conurbadas e cuja distância da relação a capital do estado é de aproximadamente $70 \mathrm{~km}$, a partir de Santos. Ao todo, a região possui aproximadamente 1.781.727 habitantes, distribuídos pelos nove municípios citados (SEADE, 2017).

O objeto deste estudo de casos múltiplos são os municípios de Cubatão, Itanhaém e Santos. A cidade de Cubatão foi edificada no sopé da Serra do Mar, que originalmente servia como ponto de parada para as pessoas que acessavam ao planalto paulista desde o litoral. Atualmente a cidade centraliza as principais ligações rodoviárias da região e concentra importante núcleo comercial e industrial.

Itanhaém localiza-se ao Sul da região e é a segunda cidade mais antiga do Brasil, fundada em 22 de abril de 1532 por Martim Afonso de Souza. O município possui grande importância dentro da história brasileira, pois foi elevada à categoria de Vila no ano de 1561 e graças às construções da época, que eram de grande porte, conquistou o status de município, sendo a segunda cidade mais antiga do país. A economia local concentra-se fortemente no turismo, no comércio e no setor de serviços.

Santos é o município sede da região e divide-se em uma área insular (zona rural e de proteção ambiental) e outra continental (núcleo urbano). A área insular corresponde a 39,4 $\mathrm{Km}^{2}$ e a parte continental a 231,6 $\mathrm{Km}^{2}$, formando uma área territorial total de $271 \mathrm{Km}^{2}$. Além da orla, da ampla rede hoteleira e de serviços executivos, a cidade é sede de um grande complexo portuário em sua região central histórica da cidade, que possui diversos atrativos e equipamentos turísticos de cunho cultural, que juntos formam alternativas para as atividades de lazer ligadas à praia. 


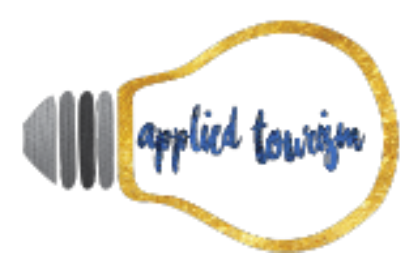

3(1), 2018, p. 147-169

Na seção seguinte são apresentados os principais resultados obtidos a partir da realização das entrevistas pessoais semiestruturadas junto aos dirigentes municipais de turismo das cidades analisadas.

\section{ANÁLISE E DISCUSSÃO DOS RESULTADOS}

A fase de pesquisa de campo foi composta, primeiro, pela aplicação de entrevistas individuais semiestruturadas junto aos dirigentes municipais de turismo e, em seguida, a dois stakebolders indicados por estes (snowball sampling) (HANDCOCK \& GILE, 2011).

\section{Entrevistas com os dirigentes municipais de turismo}

Foram realizadas entrevistas com as autoridades públicas municipais de turismo das cidades de Cubatão, Itanhaém e Santos. Respectivamente, os respondentes foram Francisco Tico Barbosa Júnior (Entrevistado 01), Milton Saldiba Passareli de Campos Junior (Entrevistado 02) e Luiz Dias Guimarães (Entrevistado 03).

As sessões foram precedidas por contato telefônico e agendadas por meio de carta convite submetida via e-mail aos Secretários citados e, após concordância, tiveram duração aproximada de 20 minutos, sendo realizadas nas sedes das Secretarias.

As entrevistas foram organizadas em duas partes, sendo a primeira voltada à identificação dos respondentes e a segunda sobre o histórico e desempenho do organismo. Nessas sessões, as citações das entrevistas são grafadas em itálico para que obtenha diferenciação do texto corrente.

Quanto a formação acadêmica, identificou-se uma variação sobre o perfil dos profissionais. Os Secretários de Turismo de Cubatão e de Santos são graduados em administração de empresas e jornalismo, respectivamente, e o Secretário de Itanhaém possui graduação incompleta em Direito. 


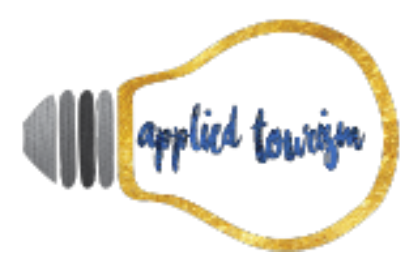

3(1), 2018, p. 147-169

Todos entrevistados possuem sólida experiência profissional fora do setor público inclusive na academia no caso do Entrevistado 03. O Entrevistado 01 possui uma empresa transportadora de cargas, que é administrada pela família e o Entrevistado 02 exerceu o cargo de Vereador durante a gestão anterior (2008-2012). Os três entrevistados possuem experiência anterior no serviço público, mas nenhum deles é concursado, tendo exercido cargos de livre nomeação. Entre os três, entretanto, cabe destacar que o Entrevistado 02 foi o único a exercer a vereança.

Os entrevistados foram convidados a citar três projetos, sejam em andamento ou concluídos. Em Cubatão as principais ações são o desenvolvimento do inventário turístico, o consequente plano diretor e a reformulação do Conselho Municipal de Turismo (COMTUR); em Itanhaém as principais ações citadas foram o Festival Gastronômico, o Festival de Hospedagem e os shows nacionais promovidos gratuitamente ao longo da temporada de verão; e em Santos foram citados o Museu Vivo Internacional de Bondes, criado em 2000 (conforme o entrevistado, a linha de bondes turísticos possui $5 \mathrm{~km}$ de extensão, 12 bondes em operação e passa por 40 pontos turísticos, tendo atendido a mais de 1.300.000 passageiros) e o Museu Pelé, que reúne acervo sobre a carreira do ex-jogador, da seleção brasileira de futebol e do Santos Futebol Clube. Adicionalmente, o Secretário de Turismo de Santos citou a contratação de consultoria externa para a elaboração do Plano Diretor de Turismo do município e a realização do Festival Santos Café.

Procedeu-se apresentação de uma definição do termo stakeholders aos entrevistados - "São todos os indivíduos, grupos ou organizações que são afetados ou afetam outros stakebolders no alcance do objetivo de uma determinada empresa [ou organização]" (FREEMAN, 1984, p. 5) - de modo que fosse possível citar três principais stakebolders da Secretaria de Turismo.

O perfil dos stakeholders citados permite considerações acerca da problemática central desta pesquisa, que é a competitividade do setor de viagens e turismo na Região metropolitana da Baixada Santista. 


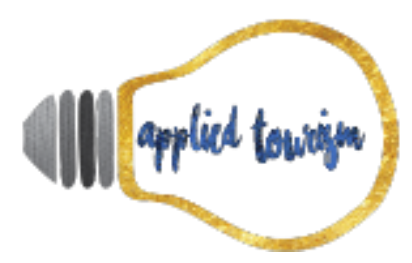

3(1), 2018, p. 147-169

As respostas variaram, pois para o Secretário de Turismo de Cubatão citou uma grande empresas sediada no polo industrial local (Unipar Carbocloro), a Secretaria de Turismo do Estado de São Paulo e a Companhia de Desenvolvimento Habitacional e Urbano, organismo vinculado ao governo estadual, o Secretário de Turismo de Itanhaém citou a Secretaria de Desenvolvimento Econômico local, a Associação Comercial de Itanhaém e o Conselho Municipal de Turismo e o Secretário de Turismo de Santos citou o Museu Pelé e o Museu do Café, entidade privada ligada a realização do Festival Santos Café.

Em Itanhaém Secretário de Turismo de Itanhaém citou a Secretaria de Desenvolvimento Econômico local, a Associação Comercial de Itanhaém e o Conselho Municipal de Turismo como os três principais stakebolders da Secretaria de Turismo local. O perfil deste grupo denota a articulação local e a sugere harmonia entre os atores do turismo na localidade.

Quando perguntados se o atendimento ou não das demandas dos atores locais influenciam o desempenho dessas organizações, os respondentes foram unânimes em responder positivamente. Isso significa que na visão dos entrevistados a ação governamental pode sim dinamizar o setor - prerrogativa essencial deste estudo.

Em Itanhaém, o Entrevistado 02 citou que a ação governamental ajuda a amenizar ou mesmo evidenciar conflitos entre os stakeholders - e entre estes e o poder público. O Secretário exemplifica a Festa do Divino, tradicional evento realizado pela comunidade católica da cidade. Por ocasião desse evento entidades assistencialistas sediadas em Itanhaém têm permissão para comercializar itens alimentícios no perímetro do evento, o que gera atritos com os comerciantes locais, pois "o comerciante paga impostos, tem funcionários registrados e tem toda a sua estrutura montada". O Secretário afirmou que "a Secretaria tenta intermediar isso, evitando vender os mesmos produtos e etc.".

O Secretário de Turismo de Santos afirmou que "o turismo se faz pelo conjunto, tem que haver sinergia permanente do poder público com o terceiro setor e também com o trade". 


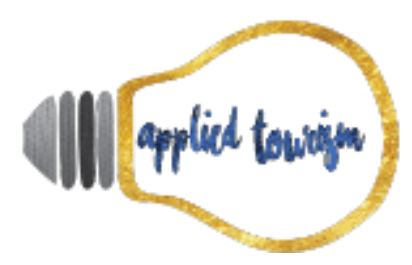

3(1), 2018, p. 147-169

O Secretário citou como importantes parceiros institucionais o Santos e Região Convention E Visitors Bureau (SRC\&VB) e o Sindicato de Hotéis, Restaurantes, Bares e Similares da Baixada Santista e Região (Sinhores).

Apresentou-se resumidamente os dados coletados a partir das entrevistas individuais semiestruturadas realizadas com Secretários Municipais de Turismo de Cubatão, Itanhaém e Santos. A próxima seção é uma compilação das respostas obtidas nas entrevistas realizadas junto aos dois stakeholders indicados por estes.

\section{Entrevistas com os stakebolders das Secretarias de Turismo}

A partir da aplicação da técnica "bola de neve" adotada nesta pesquisa, foram indicados dois stakeholders a serem entrevistados na segunda fase da pesquisa de campo.

O roteiro das entrevistas foi composto por dois blocos de perguntas, sendo o primeiro sobre o perfil profissional dos entrevistados e o segundo sobre a atividade de suas organizações em relação ao poder público local.

Os stakebolders entrevistados foram questionados sobre três principais projetos realizados, sejam concluídos ou em andamento. O objetivo dessa pergunta foi verificar em que medida os projetos de turismo ou que têm relação com a Secretaria de Turismo local são relevantes para essas organizações. Para a Delegada Regional de Turismo para Santos e Região, as principais ações da Secretaria de Turismo do Estado de São Paulo são o programa Roda São Paulo, o Sabor São Paulo e Observatório de Pássaros (em fase de planejamento). O Diretor de Projetos da Caiçara Expedições (esta empresa substituiu a Unipar Carbocloro) informou que os principais roteiros turísticos ofertados são a Canoagem ecológica, realizada no manguezal de Praia Grande e São Vicente, a Trilha da Fazenda Cabuçu, localizada na área Continental de Santos e os roteiros de Turismo de base comunitária, em especial o projeto desenvolvido na Ilha Diana, na área estuarina de Santos. 


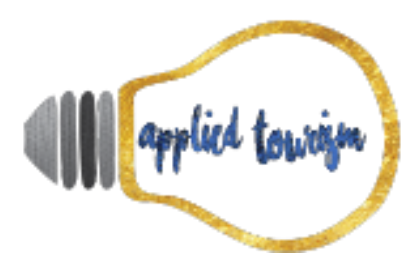

3(1), 2018, p. 147-169

O Presidente da Associação Comercial de Itanhaém citou o atendimento especializado ao Microempreendedor Individual (MEI), a representação do município junto ao Conselho de Desenvolvimento da Região Metropolitana da Baixada Santista (Condesb) e o "Projeto Empreender", que é uma ação voltada à qualificação da mão de obra operacional e gerencial da cidade.

No mesmo sentido, o Diretor de Comércio de Itanhaém citou o atendimento especializado ao Micro Empreendedor Individual (MEI), a atenção especial aos concessionários de quiosques das praias do município e o apoio a artistas locais, inserindo-os nas grades de programação dos diversos eventos locais promovidos pela Prefeitura Municipal de Itanhaém. O entrevistado se refere ao "Festival Frutos da Terra", que visa divulgar os talentos do município. Durante a temporada de verão 2014/2015 o evento ocorreu entre os dais 31 de dezembro e 4 de janeiro.

O Gerente Geral do Museu Pelé falou sobre as diversas parcerias com meios de hospedagem e agências de turismo receptivo, além da criação do pacote combo em parceria com o Memorial das Conquistas do Santos Futebol Clube, outro museu de importância regional, sediado em Santos. A Analista de Comunicação do Museu do Café citou o atendimento especializado para alunos de escolas de nível fundamental e médio (Programa Férias no Museu), a criação do BondeCafé em parceria com a Secretaria de Turismo de Santos e a realização de eventos como o Festival Santos Café, também em parceria com a Secretaria local.

Foi possível verificar que todos os stakebolders entrevistados têm ações em parceria com as instâncias de governança do turismo locais e que estas parcerias são importantes para ambos os lados. Ocorre que frequentemente os resultados dessas ações em conjunto são efêmeros, não têm continuidade e tampouco se convertem em políticas públicas municipais de turismo. 


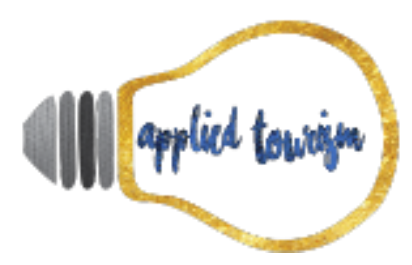

3(1), 2018, p. 147-169

Esse contexto - agravado pela carência de uma instituição estatal ou paraestatal que lidere e oriente o desenvolvimento do setor - sugere um produto turístico regional fragmentado e pouco expressivo no mercado turístico nacional. Isso não significa, entretanto, poucos visitantes ou baixas vendas nos comércios locais, por exemplo, mas um modelo de turismo baseado em viagens autônomas e em residências secundárias - fatores que precarizam a oferta de serviços nas cidades da região.

Os entrevistados foram unânimes em concordar que o relacionamento entre os diversos atores atuantes no setor de viagens e turismo em suas cidades ajuda a incrementar a oferta, contribuindo para melhorar a qualidade dos produtos e serviços e, com isso, tornam o destino mais competitivo. Todos também foram unânimes ao concordar que a ação governamental pode dinamizar o setor de viagens e turismo em níveis local e regional, o que, mais uma vez, ajuda a aumentar a competitividade das empresas do setor.

\section{CONSIDERAÇÕES FINAIS}

O objetivo da pesquisa foi identificar como a organização gestora do destino gerencia suas relações com os stakebolders do setor de viagens e turismo. A partir da análise das informações prestadas pelos entrevistados e com base no referencial teórico, verificou-se que os municípios parecem manter pouco diálogo entre si e mantém muito poucas ações conjuntas com os stakeholders indicados para promoção do turismo em nível regional.

Verificou-se que há arranjo institucional inerente ao turismo, além da ampla presença de empresas prestadoras de serviços turísticos na região. Seria positivo que espaços para o diálogo institucionalizado e formal fossem utilizados sistematicamente pelo trade regional. Entidades como o Santos e Região Convention \& Visitors Bureau e o Sindicato de Hotéis, Restaurantes, Bares e Similares da Baixada Santista e Região, além das associações comerciais locais, poderiam centralizar, operacionalizar e fomentar estes espaços. 


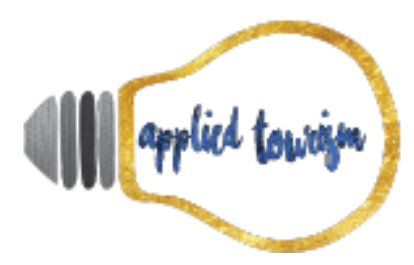

3(1), 2018, p. 147-169

Foi possível verificar que há ações consorciadas entre as organizações gestoras dos destinos e seus stakeholders, mas os resultados destas ações são pontuais e não tendem a converterem-se em políticas públicas para fortalecimento do setor como um todo ao longo do tempo.

É prerrogativa deste trabalho discutir a influência das relações de hospitalidade/hostilidade na competitividade dos destinos turísticos. Nesta pesquisa não foi proposto ou adotado modelo para aferição desta influência, cabe citar, então, elementos que constituem e caracterizam as relações de hospitalidade e sua influência positiva sobre o (bom) desempenho e, posteriormente, sobre o ganho de competitividade das mesmas e do destino como um todo.

Como visto, então, estas ações consorciadas, a articulação entre os múltiplos stakeholders atuantes na localidade, a colaboração entorno de uma organização gestora do destino e mesmo o diálogo institucionalizado, entre outros elementos, constituem e caracterizam as ditas relações de hospitalidade e hostilidade. Importa que os destinos turísticos sejam capazes de gerenciar estes relacionamentos, hora potencializando e hora mitigando suas influências sobre sua própria competitividade.

A baixa efetividade dos Conselhos Municipais do Turismo agrava o cenário encontrado à ocasião da pesquisa de campo. À época estes fóruns encontravam-se inativos e em processo de reativação - no caso de Cubatão e Itanhaém. Em Santos não houve reuniões durante o período de pesquisa de campo.

É importante citar que os Conselhos Municipais se configuram como espaços para o estabelecimento de diálogo entre mais variados atores do setor, o que influencia - ou pode influenciar - na formulação da agenda pública do setor, processo que acontece mediante disputas diversas. 


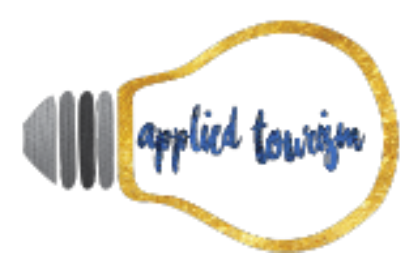

3(1), 2018, p. 147-169

Em termos práticos, tanto membros representantes do poder público quanto da iniciativa privada e do terceiro setor, são corresponsáveis pela efetividade dos Conselhos, da transparência na gestão dos mesmos assim como pela eficiência e eficácia das ações tomadas.

Verificou-se, ainda, que não há uma liderança setorial na região, o que aumenta a importância e a influência da ação governamental. Atualmente, o Plano Diretor de Turismo da Região Metropolitana da Baixada Santista encontra-se defasado dado que sua publicação original aconteceu no ano de 2003.

Outro instrumento desenvolvido pelo poder público estadual que serve como diretriz para o desenvolvimento regional do turismo é o Plano Metropolitano de Desenvolvimento Estratégico da Baixada Santista (PMDE), material apresentado ao público em 28 de maio de 2014. O PMDE constitui-se no mais recente relatório sobre o turismo em nível regional disponível. O relatório afirma que a região "caracteriza-se pela grande diversidade de vocações, atrativos e atividades turísticas presentes nos municípios que a compõem". Ocorre que "a grande maioria dos gestores públicos municipais não possui, por exemplo, um plano de ação visando reverter os efeitos negativos da sazonalidade, para buscar novos tipos de turistas". É justamente a partir desse ponto em que a ação governamental passa a fazer diferença de modo efetivo na vida do empreendedor (AGEM, 2014, 105), ou seja, já que não há um pensamento comum - materializado em uma política pública construída de modo minimamente participativo - ou o estabelecimento de uma visão compartilhada entre os múltiplos stakeholders da destinação, cada ente atuará de modo autônomo ou dentro de um grupo em particular.

A partir do referencial teórico elaborado, foram determinados os seguintes pressupostos a serem investigados: as relações de hospitalidade inerentes ao domínio comercial podem influenciar tanto positiva quanto negativamente o desempenho do setor de viagens e turismo em uma dada destinação (P1) (ratificado pelo estudo); e as organizações gestoras 


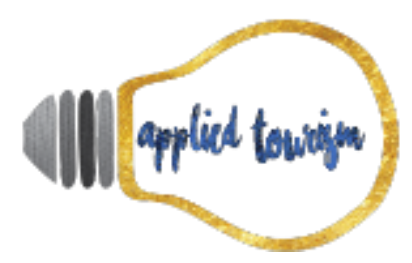

3(1), 2018, p. 147-169

dos destinos analisados têm seus stakeholders identificados e mapeados, mantendo diálogo formal com os mesmos (P2) (não ratificado pela pesquisa).

As conclusões desta investigação não esgotam o tema, mas dão pistas sobre possíveis caminhos a serem adotados por outros pesquisadores. Pesquisas quantitativas sobre o tema poderão proporcionar visões complementares sobre as relações de hospitalidade entre o poder público e seus diversos stakeholders, além de aferir a incidência de fatores que influenciam a competitividade do destino turístico.

Esta pesquisa não propôs ou adotou modelo para aferição da(s) influência(s) das relações de hospitalidade/hostilidade entre os stakebolders do poder público, no caso, na competitividade das destinações. Estudos futuros poderão, entretanto, vir a propor modelo para a sistematização desta análise.

\section{REFERÊNCIAS}

Adukaaite, A., Zyl, I. V. \& Cantoni, L. (2016). The role of digital technology in tourism education: A case study of South African secondary schools. Journal of Hospitality, Leisure, Sport E Tourism Education, 19, 54-65.

Agem. Agência Metropolitana da Baixada Santista. Plano Metropolitano de Desenvolvimento Estratégico da Baixada Santista (2014). Appril 6. $<$ http://www.agem.sp.gov.br/midia/pmdebs.pdf $>$

Altenburg, T., Hillebrand, W. \& Meyer-Stamer, J. (1998). Building systemic competitiveness: concept and case studies from Mexico, Brazil, Paraguay, Korea and Thailand. German Development Institute, 3, 1-75.

Bardin, L. (2011). Análise de Conteúdo. São Paulo: Edições 70.

Boonstra, T. W., Larsen, M. E. \& Christensen, H. (2015). Mapping dynamic social networks in real life using participants' own smartphones. Heliyon, 1, 1-21.

Brandão, I. F., Diógenes, A. S. M. \& Abreu, M. C. S. (2017). Alocação de valor ao stakeholder funcionário e o efeito na competitividade do setor bancário. Revista Brasileira de Gestão de Negócios, 19 (64): 161-179.

Caon, M. (2008). Gestão estratégica de serviços de hotelaria. São Paulo: Atlas. 


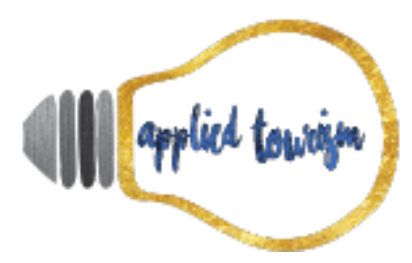

3(1), 2018, p. 147-169

Carroll, A. B. \& Buchholtz, A. K. (2003). Business and Society: Ehics and Stakeholder Management. Austrália: Thomson South Western.

Freeman, R. E. (1984). Strategic management: A stakeholder approach. Boston: Pitman.

Gibbs, G. (2009). Análise de dados qualitativos. Porto Alegre: Artmed.

Gorni, P. M. \& Dreher, M. T. (2011). Desafios intersetoriais no desenvolvimento do turismo: uma leitura das parcerias em Blumenau (SC). Caderno Virtual de Turismo, 11(1), 1-17.

Gotman, A. (2009). O comércio da hospitalidade é possível? Revista Hospitalidade, 6(2), 3-27.

Handcock, M. S. \& Gile, K. J. (2011). On the concept of snowball sampling. Cornell University Library, 1: 1-5.

Ibge. Instituto Brasileiro de Geografia e Estatística. (2017). Perfil do Estado de São Paulo. April 6. $<$ http://www.ibge.gov.br/estadosat/perfil.php?sigla $=$ sp $>$

In, S. Y., Casemiro, Luiza, A. S. \& Kim, J. (2017). A decision framework for successful private participation in the airport sector. Journal of Air Transport Management, 62: 217-225.

Junqueira, R. R. \& Wada, E. K. (2011). Stakeholders: estratégia organizacional e relacionamento. Estudo de casos múltiplos do setor hoteleiro. Revista Ibero-Americana de Estratégia, 10(3), 94-125.

Koga, E. S. (2011). Análise dos stakeholders e gestão dos meios de hospedagem: estudo de casos múltiplos na vila do Abraão, Ilha Grande (RJ). Dissertação (Mestrado em Hospitalidade). Universidade Anhembi Morumbi: São Paulo.

Lashley, C. (2000). Toward a theoretical understanding. In: Lashley, C. \& Morrison, A. (Eds.) In Search of Hospitality: Theoretical Perspectives and Debates. Oxford (UK): ButterworthHeinemann.

Line, N. D. \& Wang, Y. (2017). A multi-stakeholder market oriented approach to destination marketing. Journal of Destination Marketing $\&$ Management, 1(1), 84-93.

Miki, A. F. C., Gandara, J. M. G. \& Muñoz, D. R. M. 2012. O estado atual de pesquisas sobre competitividade turística no Brasil. Caderno Virtual de Turismo, 12(2), 212-223.

Mitchell, R. K., Agle, B. R. \& Wood, D. J. (1997). Toward a theory of stakeholder identification and salience: defining the principle of who and what really counts. Academy of Management Review, 22(4), 853-886.

Nazarian, A., Atkinson, P. \& Foroudi, P. (2017). Influence of national culture and balanced organizational culture on the hotel industry's performance. International Journal of Hospitality Management, 63, 22-32.

Panosso Netto, A. (2010). O que é Turismo. São Paulo: Brasiliense. 


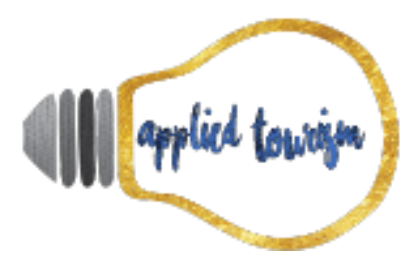

3(1), 2018, p. 147-169

Peroff, D. M., Deason, G. G., Seekamp, E. \& Iyengar, J. (2017). Integrating frameworks for evaluating tourism partnerships: An exploration of success within the life cycle of a collaborative ecotourism development effort. Journal of Outdoor Recreation and Tourism, 17, 100111.

Porter, M. (1998). Clusters and the new economics competition. Harvard Business Review, 75-90.

Porter, M. (1998). The five competitive forces that shape strategy. Harvard Business Review, 1-18.

Porter, M. (1999). Competição. Rio de Janeiro: Campus.

Resende Junior, P. C. \& Guimarães, T. A. (2012). Inovação em Serviços: o estado da arte e uma proposta de agenda de pesquisa. Revista Brasileira de Gestão de Negócios, 14(44), 239313.

Saito, H. \& Ruhanen, L. (2017). Power in tourism stakeholder collaborations: Power types and power holders. Journal of Hospitality and Tourism Management, 31, 189-196.

Seade. Fundação Sistema Estadual de Análise de Dados. Sistema Seade de Projeções Populacionais. April 6. < http://produtos.seade.gov.br/produtos/projpop/index.php $>$

Stoner, J. A. F. \& Freeman, R. E. (1999). Administração. Rio de Janeiro: Prentice Hall do Brasil.

Svensson, P. G. (2017). Organizational hybridity: A conceptualization of how sport for development and peace organizations respond to divergent institutional demands. Sport Management Review, 421, 1-12.

Theodoulidis, B., Diaz, D., Crotto, F. \& Rancati, E. (2017). Exploring corporate social responsibility and financial performance through stakeholder theory in the tourism industries. Tourism Management, 62, 173-188.

Vajirakachorn, T. \& Chongwatpol, J. (2017). Application of business intelligence in the tourism industry: A case study of a local food festival in Thailand. Tourism Management Perspectives, 23, 75-86.

Valeriano, D. L. (2001). Gerenciamento estratégico e administração por projetos. São Paulo: Makron Books.

Wada, E. K. \& Moretti, S. L. A. (2014). Hospitalidade: dos domínios às lentes e sua inserção nos processos de gestão. Caderno de Estudos e Pesquisas do Turismo, 3(3), 95-105.

Wada, E. K. (2003). Reflexões de um aprendiz de hospitalidade. In: Dencker, A. F. M., Bueno, M. S. Hospitalidade: cenários e oportunidades. São Paulo: Pioneira Thomsom Learning.

Wto. World Tourism Organization. (2003). Turismo internacional: uma perspectiva global. Porto Alegre: Bookman.

Yin, R. K. (2015). Estudo de Caso: planejamento e métodos. Porto Alegre: Bookman. 